\title{
A CONTRIBUIÇÃO DAS EXPEDIÇÕES CIENTÍFICAS PARA O \\ ENTENDIMENTO DAS MODIFICAÇÕES DA PAISAGEM URBANA \\ Daniela de Matos Carneiro ${ }^{1}$; Lilian Quelle Santos Queiroz ${ }^{2}$ e Grupo de Pesquisa e Artes-Uefs ${ }^{3}$ \\ 1. Bolsista PROBIC/UEFS, Graduando em Engenharia Civil, Universidade Estadual de Feira de Santana, e- mail: daniela.eng45@gmail.com \\ 2. Orientador, Departamento de Letras e Artes, Universidade Estadual de Feira de Santana, líder do Grupo de Pesquisa Estudos sobre Desenho, Ciência e Produção do Conhecimento dgp.cnpq.br/dgp/espelhogrupo/8457034722443852 e-mail: lilian@uefs.br \\ 3. Participante do projeto Desenho \& Ciência: Contribuições, metodologias e Métodos, Departamento de Letras e Artes, Universidade Estadual de Feira de Santana
}

PALAVRAS-CHAVE: Desenho; História da Ciência; Produção do Conhecimento.

\section{INTRODUÇÃO}

Durante a estada da família real portuguesa no Brasil, chega ao Rio de Janeiro em 1816, a Missão Artística Francesa organizada por Joaquim Lebreton, secretário da seção de belas-artes do Instituto de França, e composta por alguns dos mais renomados artistas da época: Jean Baptiste Debret, Nicolas Taunay, Auguste Taunay, escultor; Grandjean de Montigny, arquiteto; Simon Pradier, gravador e entalhador; Francisco Ovide, professor de mecânica aplicada; Francisco Bonrepos, ajudante de escultor; Segismund Neukomm, músico e discípulo do compositor austríaco Franz Joseph Haydne composta por um grupo artistas plásticos. O principal objetivo do grupo era ensinar artes plásticas e a criação de uma academia de artes e ciências no Brasil, eles pintavam, desenhavam, esculpiam e construíam à moda européia, obedecendo ao estilo neoclássico.

A vinda da Missão Artística Francesa com a tarefa de estabelecer uma Escola Real de Ciências, Artes e Orifícios, a fim de difundir conhecimentos na colônia portuguesa contribuiu significativamente, acabou para a produção de conhecimento influenciando o cenário artístico brasileiro, além de estabelecer um ensino acadêmico inexistente até então.

A arte também começou a ser revista, de modo a reproduzir no Brasil o universo europeu, com inspiração vinda da França. A Missão Francesa passou a reproduzir no Brasil rumos artísticos nunca vistos, antes de 1816, a arte da região seguia com rigidez os cânones religiosos.

\section{MATERIAL E MÉTODOS OU METODOLOGIA (ou equivalente)}

A pesquisa teve início com fontes bibliográficas e imagéticas. Em primeiro momento foi feito um aporte sobre as expedições científicas no Brasil, principalmente, sobre a Missão Artística Francesa. Em seguida foi estudado sobre os principais artistas da Missão, traçado um perfil e identificado as obras de cada um.

Em seguida a fundamentação teórica para a argumentação do projeto se baseou na importância das expedições.

Arquivos do Enciclopédia Cultural foram consultados e mais tarde foi feito uma linha do tempo com obras e artistas que contribuiu para difundir o ensino de belas artes no Brasil. 
Na tripulação de Pedro Alvares Cabral estava o escrivão Pero Vaz Caminha, que descreveu o que encontrou no país ao chegar, foi o primeiro marco da nossa história e um dos principais documentos das expedições científicas no Brasil. Começa o escrivão: "Andávamos por aí vendo o ribeiro, o qual é de muita agua e muito boa. Ao longo dela há muitas palmeiras, não muito altas, e muito bons palmitos" (Caminha apud MelloLeitão, 1941, p.28). A exploração no Brasil só havia começado, após explorar o litoral eles partiram para a navegação nos rios, e passaram a observar os planaltos, a terra e as suas riquezas, a fauna, flora e o homem.

Segundo Mello-Leitão, as expedições científicas intensificaram no Brasil em 1808, quando Portugal estava preste a ser invadido pelas tropas francesas comandadas por Napoleão Bonaparte e então o príncipe regente de Portugal, D. João, veio com a corte portuguesa para cá. E em 1815, chegou a primeira oficial expedição científica que foi destinada ao Brasil organizada por Portugal e Holanda.

Segundo o Jornal da PUC (2016), o maior legado da Missão Artística foi ter instituído no Brasil um conceito mais erudito de arte. Eles trouxeram o que se entendia no Ocidente nesse campo para o Brasil. Até então, não havia a ideia do artista ou do arquiteto, as pessoas conheciam o artesão, mas os franceses apresentaram a ideia de um ensino artístico oficial. Havia um padrão de sobrados coloniais de ruas contínuas de dois a três pavimentos, no máximo. Construções associadas ao signo do atraso. De resto, chácaras, sítios e áreas alagadiças. Não havia uma arquitetura civil nobre, palácios. Por essa razão, era necessário atribuir à cidade uma transformação que estivesse em sintonia com o novo status da capital do Reino.

A Missão Artística Francesa era composta por artistas de sólida formação acadêmica, identificados com os princípios estéticos neoclássicos, como o pintor de paisagem Nicolas Antoine Taunay (1755-1830), seu irmão, o escultor Auguste Marie Taunay (1768-1824), o também pintor e desenhista Jean Baptiste Debret (1768-1848), o gravador Charles Simon Pradier (1783-1847) e o arquiteto Auguste Henri Victor Grandjean de Montigny (1776-1850); além do professor de mecânica François Ovide e alguns especialistas em ofícios mecânicos (serralheiro, ferreiro, carpinteiro, curtidor). No ano seguinte, chegaram ao Brasil, para juntarem-se aos seus compatriotas, o escultor Marc Ferrez (1788-1850) e o gravador Zéphyrin Ferrez (1797-1851), que eram irmãos.

Obras da Missão Artística Francesa:

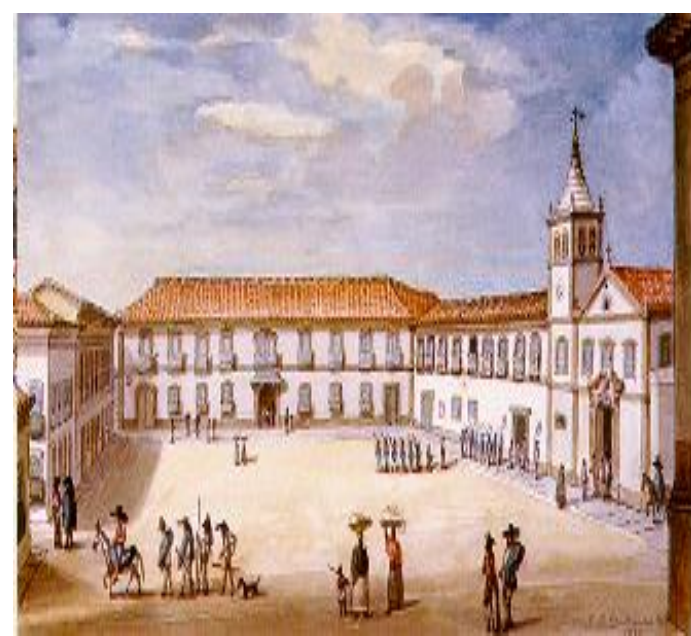

Figura 1: Palácio do governo em São Paulo

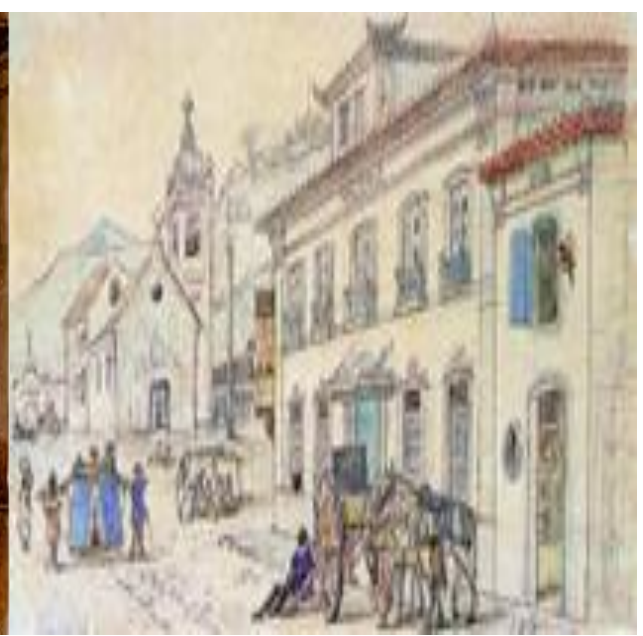

Figura 2: Casário 


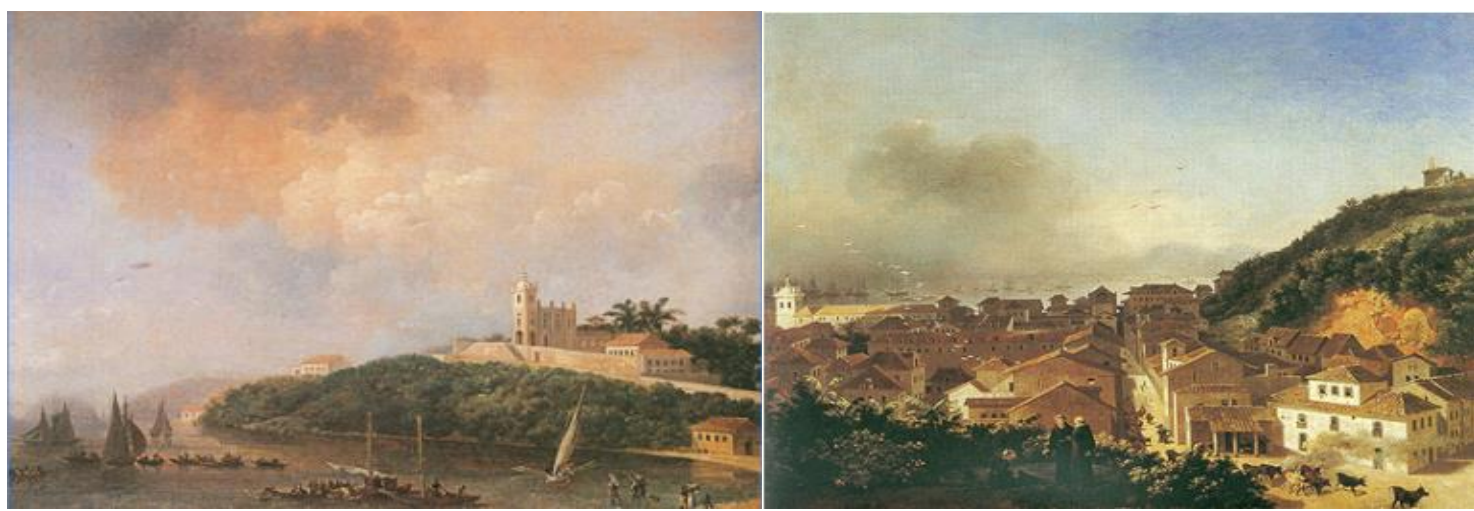

Figura 3: Vista do Outeiro, Praia e Igreja da Glória.

Figura 4: Largo do Carioca

Grandjean de Montigny

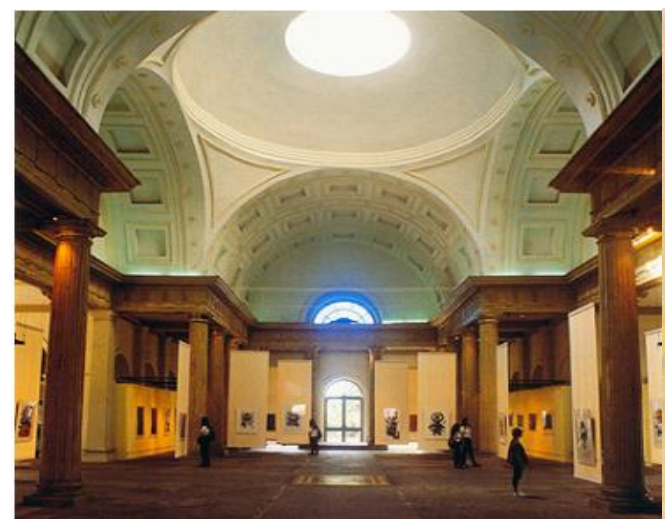

Figura 5: Edifício da Praça do Comércio, no Rio de Janeiro

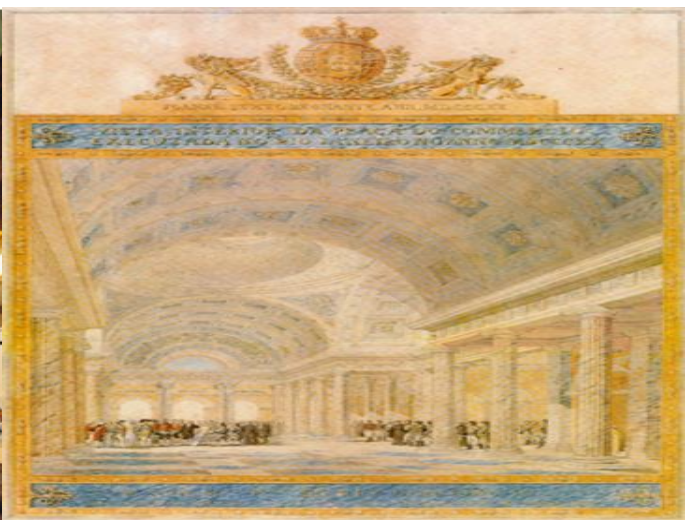

Figura 6: Vista Interior da Praça do Comércio.

\section{CONSIDERAÇÕES FINAIS (ou Conclusão)}

Este plano de trabalho buscou tecer relações entres as expedições científicas e a modificações da paisagem. Partindo do pressuposto que durante as expedições os relatos de forma de desenho e pinturas naturalistas, ou seja, como tais como se apresentavam na natureza onde se encontravam, possibilitou uma apreensão de elementos de amplos aspectos a saber geológico, mofológico, topográfico para o entendimento da modificação da paisagem.

\section{REFERÊNCIAS}

CHAGAS, Mário de Souza. Há uma gota de sangue em cada museu: a ótica museológica de Mário de Andrade. 1999.

HERSCHMAM, Micael; KROPF, Simone; NUNES, Clarice. Missionários do Progresso: Médicos, Engenheiros e Educadores no Rio de Janeiro- 1870-1937. Diadorim Editora, Rio de Janeiro, 1996.

MELLO-LEITÃO, C. de. História das expedições científicas no Brasil. Companhia. Vol. 209, Companhia editora nacional, 1941; 
BERGAMO, Geraldo Antonio; BERNARDES, Marisa Rezende. Produção de conhecimento. Educ. Soc., Campinas, v. 27, n. 94, p. 179-198, 2006.

CHOO, Chun Wei. A organização do conhecimento: Como as organizações usam a informação para criar significado, construir conhecimento e tomar decisões. 6ed. São Paulo: Ed. SENAC, 2006.

NONAKA, I.; TAKEUCHI, H. Criação do conhecimento na empresa: como as empresas japonesas geram a dinâmica da inovação. Rio de Janeiro: Campus, 1999.

ARAUJO,Carlos Alberto Ávilas.A ciência como forma de conhecimento. Ciência e Cognitação, Minas Gerais, 15 agosto 2006. Disponível em: $<$ http://pepsic.bvsalud.org/pdf/cc/v8/v8a14.pdf >. Acesso em: 9 abril 2017.

TREVISAN, Anderson Ricardo. Debret e a Missão Artística Francesa de 1816: aspectos da constituição da arte acadêmica no Brasil. Plural (São Paulo. Online), v. 14, p. 9-32, 2007. 